\section{OCEAN CIRCULATION}

\section{Interglacial instability of North Atlantic Deep Water ventilation}

\author{
Eirik Vinje Galaasen ${ }^{1 *}$, Ulysses S. Ninnemann ${ }^{1}$, Augustin Kessler ${ }^{2}$, Nil Irvalı ${ }^{1}$, Yair Rosenthal ${ }^{3}$, \\ Jerry Tjiputra ${ }^{2}$, Nathaëlle Bouttes ${ }^{4}$, Didier M. Roche ${ }^{4,5}$, Helga (Kikki) F. Kleiven ${ }^{1}$, David A. Hodell ${ }^{6}$
}

Disrupting North Atlantic Deep Water (NADW) ventilation is a key concern in climate projections. We use (sub)centennially resolved bottom water $\delta^{13} \mathrm{C}$ records that span the interglacials of the last 0.5 million years to assess the frequency of and the climatic backgrounds capable of triggering large NADW reductions. Episodes of reduced NADW in the deep Atlantic, similar in magnitude to glacial events, have been relatively common and occasionally long-lasting features of interglacials. NADW reductions were triggered across the range of recent interglacial climate backgrounds, which demonstrates that catastrophic freshwater outburst floods were not a prerequisite for large perturbations. Our results argue that large NADW disruptions are more easily achieved than previously appreciated and that they occurred in past climate conditions similar to those we may soon face.

A tlantic Meridional Overturning Circulation (AMOC) and North Atlantic Deep Water (NADW) ventilation represent a low-probability, high-impact tipping point in the climate system (1), with implications for the distribution and sequestration of anthropogenic $\mathrm{CO}_{2}$ and heat and for Atlanticwide patterns of climate and sea level (2-4). Although the consequences of any changes are clearly severe, the probability of instabilities in the rate or pathways of NADW ventilation remains highly uncertain. Both simple and complex models suggest large changes are possible but also that a strong overturning, like that found in the modern ocean, may be more difficult to disrupt than an overall weaker circulation (4-6). Likewise, most models simulate moderate to no reduction in $\mathrm{AMOC}$ in response to future source region buoyancy increases (1), but these models may be biased toward stability (7) and struggle to reproduce the rich spectrum of variability revealed by a decade of observations $(8,9)$. Testing these physical and conceptual models, and, more generally, the stability of $\mathrm{NADW}$ ventilation in warm climates, requires empirical constraints beyond those provided by the current state of ocean circulation.

Given a background climate that is similar to that of today, the modern mode of deep Atlantic ventilation with strong NADW influence (Fig. 1) appears to be stable on long multi-millennial time scales. Proxy reconstruc-

\footnotetext{
Department of Earth Science and Bjerknes Centre for Climate Research, University of Bergen, Bergen, Norway. ${ }^{2}$ NORCE Norwegian Research Centre, Bjerknes Centre for Climate Research, Bergen, Norway. ${ }^{3}$ Institute of Marine and Coastal Sciences and Department of Earth and Planetary Sciences, Rutgers University, New Brunswick, NJ, USA. ${ }^{4}$ Laboratoire des Sciences du Climat et de l'Environnement, LSCE/IPSL, CEA-CNRS-UVSQ, Université Paris-Saclay, Gif-sur-Yvette, France. ${ }^{5}$ Earth and Climate Cluster, Department of Earth Sciences, Vrije Universiteit Amsterdam, Amsterdam, Netherlands. ${ }^{6}$ Godwin Laboratory for Paleoclimate Research, Department of Earth Sciences, University of Cambridge, Cambridge, UK.

*Corresponding author. Email: eirik.galaasen@uib.no
}

tions indicate that modern NADW ventilation pathways persisted with little multi-millennial variability in recent interglacial periods (10-14). By contrast, pronounced AMOC variability has occurred on time scales of a decade or less in observations $(8,9)$, which suggests that strong mean overturning is composed of substantial variance. However, little is known about NADW variability on the intermediary time scales, which leaves the variability within a long-term vigorous mean ventilation state poorly defined. There are few proxy reconstructions that depict higherfrequency variability, and those that are available are largely confined to the last two interglacials, the Holocene and Marine Isotope Stage (MIS) 5e. During these periods, the largest changes in deep Atlantic ventilation involving reductions of NADW influence occurred on relatively short centennial time scales and were focused around intervals with wasting of continental ice sheet remnants from the preceding glaciation $(10,12,15)$. This includes the century-long NADW reduction at 8.2 thousand years (ky) before present (B.P.) that followed the freshwater outburst flood from glacial Lake Agassiz (12). The absence of similarly large changes in the last $\sim 8 \mathrm{ky}$ of the Holocene (12) has supported the notion of vigorous and stable ventilation as generally representative of interglacial boundary conditions.

Beyond the last two interglacials, little is known about centennial-scale variability in NADW, despite its relevance for delimiting the natural variability of ocean ventilation and the frequency of large NADW reductions under different background climates. The most recent interglacials, MIS 5e, 7e, 9e, and 11c, are particularly relevant, as these periods had similar climate boundary conditions to the current MIS 1. These interglacials also encompass intervals of high-latitude warmth, Greenland Ice Sheet (GrIS) retreat, and sea level exceeding the modern (16-18). These case examples provide an opportunity to test the robustness of NADW ventilation under various source-region conditions, including those similar to future projections (1). In this work, we reconstruct northwest Atlantic bottom water $\delta^{13} \mathrm{C}$ to trace NADW influence (Fig. 1) over MIS 7e, 9e, and 11c and to provide a detailed perspective on NADW ventilation instability during recent interglacials.

Our epibenthic foraminifera Cibicidoides wuellerstorfi (sensu stricto) $\delta^{13} \mathrm{C}$ record (19) from the International Ocean Drilling Program (IODP) Site U1305 $\left(57^{\circ} 29^{\prime} \mathrm{N}, 48^{\circ} 32^{\prime} \mathrm{W} ; 3459 \mathrm{~m}\right.$ water depth) at the Eirik Drift is situated to monitor lower NADW entering the deep Atlantic (Fig. 1). Given the potential for uncertainty in $\delta^{13} \mathrm{C}$ reconstructions (20), we only consider changes in the running mean of three samples [averaging five data points; see (19)] and signals outside the standard error of data within this window to reflect bottom water $\delta^{13} \mathrm{C}$ variability. With negligible influence from organic carbon fluxes (21), this method provides a proxy for past changes in the ventilation and distribution of water masses $(20,22)$. The Eirik Drift bottom water $\delta^{13} \mathrm{C}$ record indicates large changes in deep Atlantic carbon chemistry during the interglacial $\delta^{18} \mathrm{O}$ plateaus of MIS 7e, 9e, and 11c (Fig. 2). Each interglacial contained abrupt changes in bottom water $\delta^{13} \mathrm{C}$ as large [ $\leq 1.0 \%$ (per mil)] as those of the bordering glacial terminations and inceptions (Fig. 2) and similar to those occurring after freshwater outburst floods, such as the $\sim 8.2$ ky B.P. event
Fig. 1. Core locations. IODP Site U1305 (57²9'N, 4832'W; 3459 m), MD03-2664 (57 $26^{\prime} \mathrm{N}, 48^{\circ} 36^{\prime} \mathrm{W}$; $3442 \mathrm{~m}), \mathrm{MD03}-2665\left(57^{\circ} 26^{\prime} \mathrm{N}\right.$, $\left.48^{\circ} 36^{\prime} \mathrm{W} ; 3440 \mathrm{~m}\right)$, and IODP Site

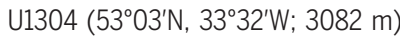
projected on a western Atlantic north-south section of preindustrial $\delta^{13} \mathrm{C}\left(\delta^{13} \mathrm{C}_{\mathrm{PI}}\right)(22)$, plotted using Ocean Data View. Core sites depicted in the data composites of Fig. $3 \mathrm{C}$ are included (light and dark purple circles). Inset, plotted using GeoMapApp, shows the key subpolar core sites including MD99-2227 (58 $\left.21^{\prime} \mathrm{N}, 48^{\circ} 37^{\prime} \mathrm{W} ; 3460 \mathrm{~m}\right)$ and the main spreading pathways of Nordic Seas-sourced deep water contributing to lower NADW (red). EQ, equator.

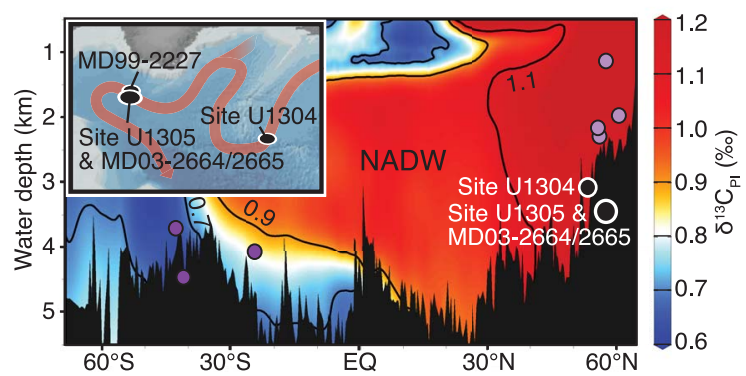


(12) and during MIS 5e (10). Absolute values range from near-modern NADW levels $(\geq 0.8 \%$; Fig. 1) to those typical of the glacial deep Atlantic $(13,14,23,24)$. Although similar in magnitude, the frequency, timing, and duration of these changes differ among individual interglacial periods. Low bottom water $\delta^{13} \mathrm{C}$ values persist for a millennium or more during late MIS 7e [ 233.5 to $243.5 \mathrm{ky}$; on our age model, (19)] and during mid- to late MIS 9e ( 323.0 to $326.0 \mathrm{ky})$, whereas large $(\sim 0.5 \%$ o) multi-centennial variability punctuated MIS 11c superimposed on multi-millennial trends.

Low bottom water $\delta^{13} \mathrm{C}$ values at Site U1305 likely reflect reduced NADW influence and changes in deep Atlantic ventilation patterns. Reduced (high- $\delta^{13} \mathrm{C}$ ) NADW influence and incursions of (low- $\left.\delta^{13} \mathrm{C}\right)$ Southern source water (SSW) explain many features of the observed variability, including (i) the spatial consistency of intermittently low $\delta^{13} \mathrm{C}$ observed at different deep sites (Site U1304 and U1305; Fig. 3); (ii) the abruptness of the $\delta^{13} \mathrm{C}$ changes as the NADW-SSW water mass boundary shifted across the core sites; (iii) the shift of Site U1305 $\delta^{13} \mathrm{C}$ toward the millennially averaged values found near the northern or the southern source regions (Fig. 3); and (iv) the association of high (low) C. wuellerstorfi $\delta^{13} \mathrm{C}$ with high (low) $C$. wuellerstorfi $\mathrm{B} / \mathrm{Ca}$ in selected Eirik Drift samples (fig. S6) (19).

We further use a transient interglacial (115 to $125 \mathrm{ky}$ ) simulation (19) with the isotopeenabled intermediate complexity iLOVECLIM Earth system model (25) to assess potential links between variability in deep Atlantic $\delta^{13} \mathrm{C}$, NADW distribution, and AMOC. Simulated centennial-scale episodes of NADW shoaling and SSW expansion produce $\delta^{13} \mathrm{C}$ reductions in the deep Atlantic that strongly match the magnitude, rate, and duration of the variability observed in our (Fig. 4) and other reconstructions (10, 12-14), consistent with the inference that the $\delta^{13} \mathrm{C}$ variability reflects changes in NADW distribution. These large deep Atlantic $\delta^{13} \mathrm{C}$ changes, which are similar in magnitude to glacial millennial-scale changes $(23,24)$, were achieved without a total collapse of but with a marked ( 16 to $\sim 8$ sverdrup) decrease in AMOC strength, and they were accompanied by cooling in the subpolar North Atlantic (Fig. 4).

Our results call for a reconsideration of the long-held notion of warm-climate stability in deep Atlantic carbon chemistry and ventilation. This view of stability likely remains true for the (multi-)millennial mean state, as previously depicted by lower-resolution records that lack the fidelity to resolve the shorter time scale characteristic of interglacial NADW reductions (Fig. 3). High-resolution records are naturally biased toward the youngest strata and the current interglacial, the Holocene. Yet, when contextualized against the late Pleistocene interglacials, the Holocene stands out as having

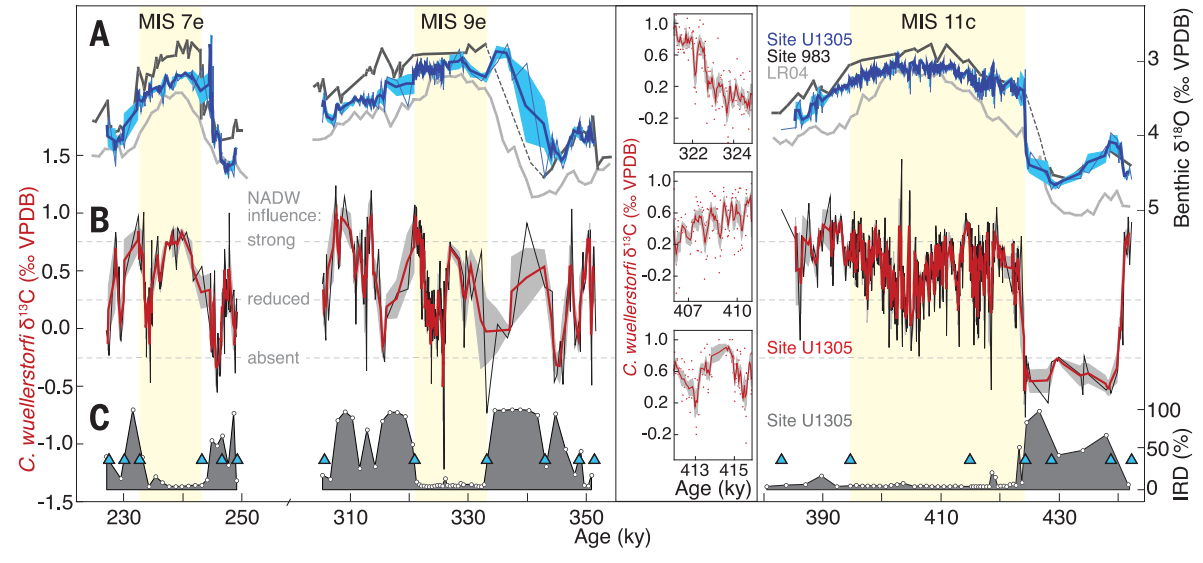

Fig. 2. IODP Site U1305 MIS 7e, 9e, and 11c C. wuellerstorfi stable isotope and ice-rafting records.

(A) Benthic $\delta^{18} 0$ from IODP Site U1305 (thin blue line, sample average of replicate measurements; bold dark blue, three-point running mean; shading, the standard error of the three-point window), age model tuning target ODP Site $983\left(60^{\circ} 23^{\prime} \mathrm{N}, 23^{\circ} 38^{\prime} \mathrm{W} ; 1983 \mathrm{~m}\right)$ (black; dashed lines denote prolonged gaps) (33), and LR04 for reference (gray) (34). (B) Site U1305 C. wuellerstorfi $\delta^{13} \mathrm{C}$ (black, sample average; red, three-point running mean; shading, standard error of three-point window) with dashed horizontal lines denoting approximate levels of inferred NADW influence. (C) Position of age model tie points (triangles) and Site U1305 IRD (percent of $>150 \mu$ m entities; black and gray) (19). All records are on the LR04 time scale (19). The sample spacing gives the benthic stable isotope records a nominal time resolution of $\sim 70$ years during the interglacial benthic $\delta^{18} \mathrm{O}$ plateaus (shaded yellow). Insets show examples of the $\mathrm{C}$. wuellerstorfi $\delta^{13} \mathrm{C}$ variability [coloring as in (B), individual data as dots]. VPDB, Vienna Pee Dee Belemnite standard.

had the most stable lower NADW ventilation of the last 0.5 million years (Fig. 3), which was only strongly curtailed at $\sim 8.2 \mathrm{ky}$ B.P. (12). Bottom water $\delta^{13} \mathrm{C}$ and NADW reductions similar to those at $\sim 8.2 \mathrm{ky}$ B.P. were prevalent features of prior interglacials, and these features even occasionally lasted for millennia (Fig. 3). Ventilation patterns changed repeatedly from one similar to the modern pattern (Fig. 1) to one with reduced NADW and incursions of SSW in the deep North Atlantic $(\sim 3.4 \mathrm{~km})$, which is similar to the change illustrated by our model simulation (Fig. 4).

The short duration of interglacial NADW reductions might indicate a change in the intrinsic ocean dynamics operating under different background climate states. The interglacial deep Atlantic is clearly better ventilated than the glacial on long equilibrium time scales $(11,13,14,23,24)$. However, the magnitude of ventilation pattern changes that are possible appears to be similar in (de)glacial $(11,24,26)$ and interglacial periods when variability in lower NADW is considered at shorter time scales (Fig. 3). The centennial-scale duration and transient nature of most interglacial NADW reductions (Fig. 3 and Fig. 4) suggest that the modern ventilation pattern tends to recover quickly when perturbed and is similar to the AMOC recovery time scale seen in many numerical models forced with buoyancy increases (4). With this in mind, the longer-lasting NADW reductions in MIS 7e ( 233.5 to $234.5 \mathrm{ky}), 9 \mathrm{e}$ ( 323 to $326 \mathrm{ky}$ ), and late 11c ( 401 to $408 \mathrm{ky}$ ) either required more sustained forcing or sug- gest that the recovery time scale following perturbations is not fixed. Most interglacial NADW reductions were still short-lived compared with those associated with glacial (DansgaardOeschger) variability (24), which suggests that either NADW ventilation behaved differently or the persistence of any forcing changed, depending on the climate state. One possible explanation for this time scale difference is the extensive glacial expansion of high-latitude sea ice, which could promote a baseline increase in SSW ventilation (27) and prolong the duration of northern ventilation anomalies (28). A lack of strong sea ice responses could also explain the potentially muted climate variability in interglacial compared with glacial climates $(10,13,14,29)$, despite the presence of NADW variability. However, more high-resolution climate records spanning past interglacials are needed to conclusively evaluate the impacts of warm-climate NADW reductions and delineate its role relative to feedbacks, such as sea ice responses, in driving interglacial climate variability.

Model simulations suggest that future warming and freshwater addition from an intensified hydrological cycle and ice sheet melting could increase source region buoyancy and curtail convective NADW renewal $(1,4)$. The common occurrence of NADW reductions in past interglacials (Fig. 3) clearly demonstrates the potential for large changes in deep Atlantic ventilation and allows us to explore the triggers for perturbations. NADW reductions during the last two interglacial periods were mainly 
confined to the early warm interglacial phases, concurrent with high northern hemisphere summer insolation and known freshwater outburst floods that accompanied the final retreat of residual glacial ice sheets (Fig. 3)
$(10,12,30,31)$. Although stratigraphically belonging to interglacial periods-to the extent that they are related to wasting vestiges of glaciation-these anomalies are likely best viewed, mechanistically, as the final episodes of deglaciation. By contrast, NADW reductions in MIS 7e, 9e, and 11c occurred in the mid- and late interglacial phases under low summer insolation (Fig. 3) and after any likely deglacial freshwater influences. This implies that NADW
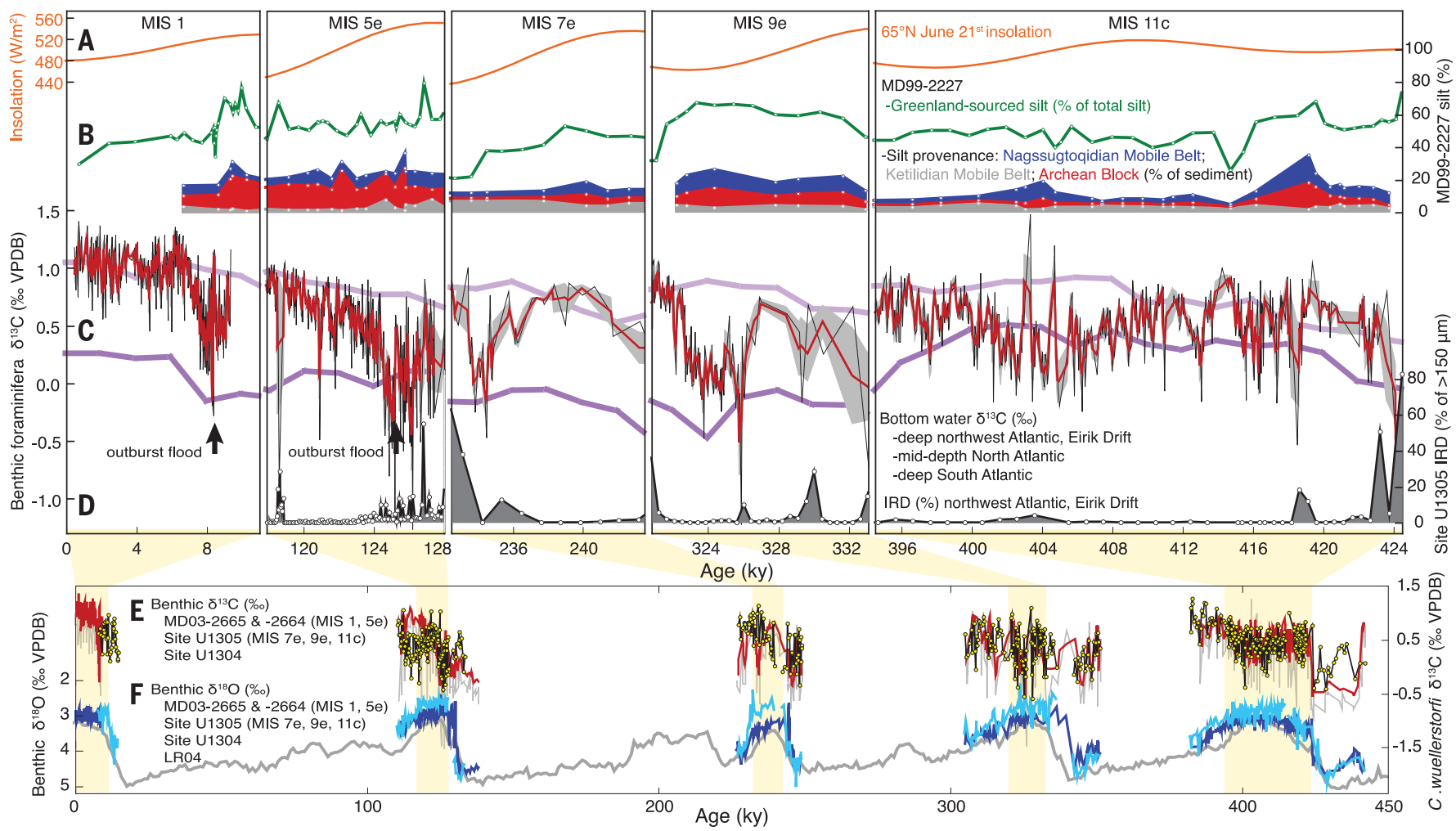

Fig. 3. Variability in NADW ventilation during interglacials MIS 1 to 11 c.

(A to D) Focused on the interglacial $\delta^{18} 0$ plateaus: (A) $65^{\circ} \mathrm{N}$ insolation at 21 June (orange) (35); (B) core MD99-2227 records of GrIS sediment discharge showing silt sourced from Precambrian Greenland terranes (green, percent of total silt) (32) and from different Greenland provenances (percent of sediment: colored, see text inset) $(18,32,36)$; (C) bottom water $\delta^{13} \mathrm{C}$ reconstructions from mid-depth North (light purple) (23) and deep South Atlantic composites (dark purple) (37) (see Fig. 1 for locations) and from the deep Eirik Drift [MIS 1: (12); MIS 5e: (10); MIS 7e, 9e, and 11c: this study] (coloring as in Fig. 2) with arrows denoting freshwater outburst floods as determined in $(10,12)$; and (D) Eirik Drift IRD records [MIS 5e: (10); MIS 7e, 9e, and 11c: (19)]. (E and $\mathbf{F}$ ) Glacial-interglacial records of (E) C. wuellerstorfi $\delta^{13} \mathrm{C}$ from the Eirik Drift [as in (C); gray line, sample average; red line, three-point mean] and IODP Site U1304 (black and yellow, sample average) $(15,38)$ (resolution, U1305: 70 years; U1304: 300 years); (F) Benthic foraminifera $\delta^{18} \mathrm{O}$ from the Eirik Drift and Site U1304 (colored, see inset; references as for $\delta^{13} \mathrm{C}$ ) and LRO4 (gray) (34). All records are plotted on the LR04 time scale (19).
Fig. 4. Modeled and reconstructed deep Atlantic $\delta^{\mathbf{1 3}} \mathbf{C}$ changes. (A and $\mathbf{B}$ ) The iLOVECLIM simulated $\delta^{13} \mathrm{C}$ distribution and Eirik Drift core location (red circle) along a north-south transect (inset) averaged for years with $(A)$ strong, modern-like AMOC (>2б; $16.75 \pm 0.70$ sverdrup mean; $n=460$ model years) and NADW distribution; and (B) weaker AMOC $(<2 \sigma ; 8.00 \pm 0.42$ sverdrup mean; $n=63$ model years) and shoaled NADW [see (19) for details]. Sv, sverdrup. (C to E) Across two simulated NADW shoaling events (10-year mean values): (C) subpolar North Atlantic mean sea surface temperature (SST; light and dark blue); (D) AMOC stream function at $27^{\circ} \mathrm{N}$ (light and dark gray); and (E) Eirik Drift bottom water $\delta^{13} \mathrm{C}$ changes [light and dark gray; magnitude similar for different preformed $\delta^{13} \mathrm{C}$ values, see (19)] compared to the reconstructions by aligning at the last high $\delta^{13} \mathrm{C}$ values. To illustrate common features that account for interglacial differences in preformed $\delta^{13} \mathrm{C}$ values, the reconstructed events are shown as the average (bold lines) of multiple events (thin lines) at 30-year steps (obtained by linear interpolation), binned according to durations of $\leq 100$ (red; $n=5$ ), 101 to 200 (blue; $n=4$ ), and 201 to 300 years (green; $n=3$ ).
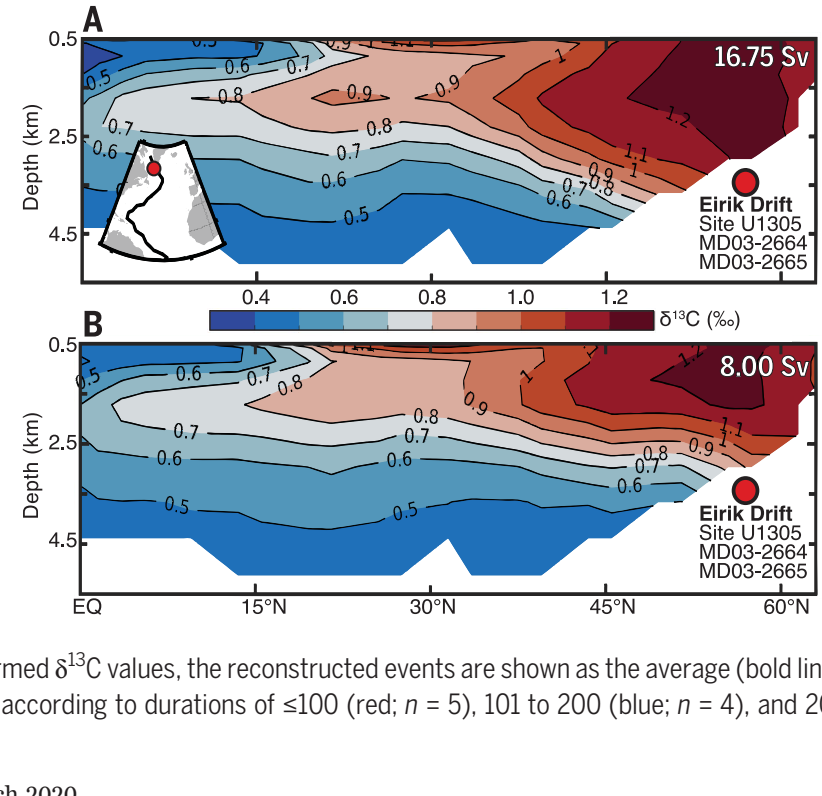

$8.00 \mathrm{~Sv}$
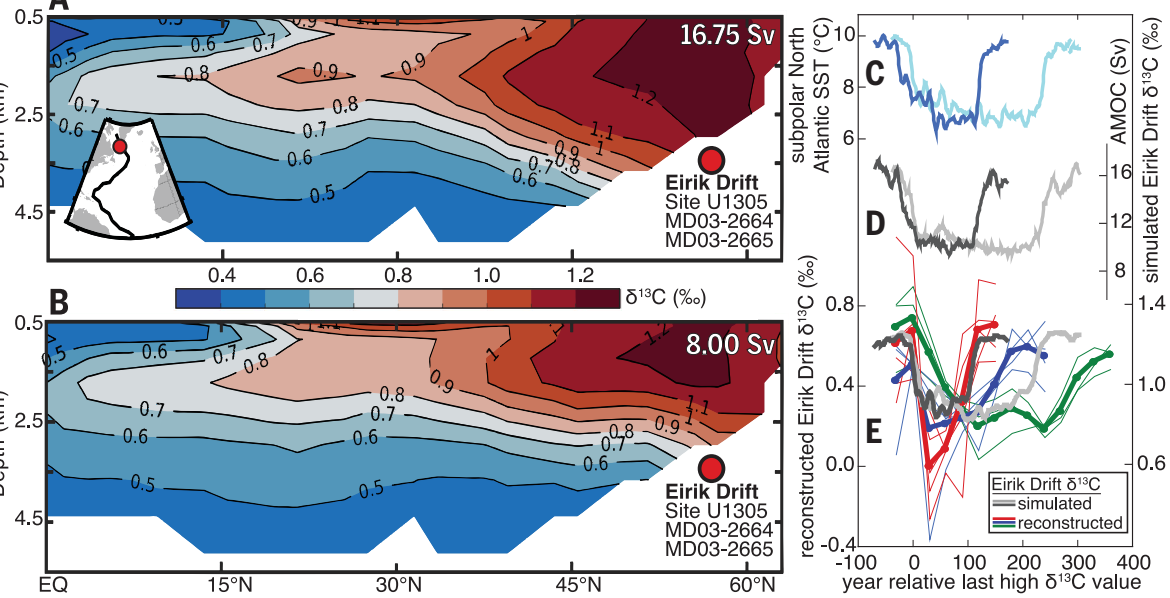
reductions can occur without the excess buoyancy input provided by wasting residual glacial ice sheets or the influence of large continental ice sheets on atmospheric circulation. However, interglacial ice sheet activity might still have played a role in regulating the stability of NADW ventilation during some intervals. NADW reductions in MIS 7e, 9e, and 11c often coincided with, or were preceded by, the input of icerafted debris (IRD) at Site U1305 (Fig. 3), which indicates a supply of icebergs and fresh water proximal to the NADW source region. Furthermore, the prolonged NADW reduction of MIS 9e was associated with elevated southern GrIS sediment discharge and MIS 1 stability was associated with low GrIS activity (32), whereas particularly strong GrIS retreat in MIS 11c $(16,18)$ occurred alongside persistent NADW variability (Fig. 3). These observations are consistent with ice sheet activity and freshwater addition intermittently influencing the formation or downstream density of lower NADW. However, variability in NADW ventilation, IRD input, and GrIS discharge also occurred independently of each other (Fig. 3), which implicates additional controls on NADW ventilation and supports models that suggest that convective instability is possible with relatively small buoyancy input if delivered to the convection regions (6).

Our results suggest that we should consider rapid and large changes in NADW ventilation not only as a possibility $(10,12,30)$ but even as an intrinsic feature of centennial-scale variability in warm climate states. This has implications for constraining the potential for and cause of changes in the modern Atlantic. First, it supports the concerns that disregarding large variability in simulations may have biased future AMOC projections toward stability (7). The possibility of large, natural variability on decadal $(8,9)$ to centennial time scales (Fig. 3) also complicates the attribution of variability in the deep Atlantic, but the characteristics of this variability may be used to differentiate between natural and anthropogenic changes in the coming century. Although past changes were predominantly multi-centennial, there are also climate and ocean conditions that can drive longer NADW reductions, as evidenced, for example, by the $~ 3000$-years-long anomaly in mid-MIS 9e (Fig. 3). Specifically what these conditions were remains unclear, but the triggers for NADW instability have clearly operated across the range of recent interglacial climate conditions. Recognizing this requires moving beyond the notion of vigorous and stable deep Atlantic ventilation as representative of warm climate states $(1,5,11)$ and toward conceptual and numerical models that can account for pronounced variability across various time scales and climate states.

\section{REFERENCES AND NOTES}

1. T. F. Stocker et al., Eds., Climate Change 2013: The Physical Science Basis: Working Group I Contribution to the Fifth Assessment Report of the Intergovernmental Panel on Climate Change (Cambridge Univ. Press, 2013).

2. M. W. Buckley, J. Marshall, Rev. Geophys. 54, 5-63 (2016).

3. C. L. Sabine et al., Science 305, 367-371 (2004).

4. T. F. Stocker, A. Schmittner, Nature 388, 862-865 (1997).

5. H. Stommel, Tellus 13, 224-230 (1961)

6. T. F. Stocker, D. G. Wright, Nature 351, 729-732 (1991).

7. M. Hofmann, S. Rahmstorf, Proc. Natl. Acad. Sci. U.S.A. 106 20584-20589 (2009).

8. M. A. Srokosz, H. L. Bryden, Science 348, 1255575 (2015).

9. M. S. Lozier et al., Science 363, 516-521 (2019).

10. E. V. Galaasen et al., Science 343, 1129-1132 (2014).

11. J. F. Adkins, E. A. Boyle, L. Keigwin, E. Cortijo, Nature 390 154-156 (1997).

12. H. K. F. Kleiven et al., Science 319, 60-64 (2008).

13. J. F. McManus, D. W. Oppo, J. L. Cullen, Science 283, 971-975 (1999)

14. D. W. Oppo, J. F. McManus, J. L. Cullen, Science 279 1335-1338 (1998).

15. D. A. Hodell et al., Earth Planet. Sci. Lett. 288, 10-19 (2009).

16. A. de Vernal, C. Hillaire-Marcel, Science 320, 1622-1625 (2008).

17. Past Interglacials Working Group of PAGES, Rev. Geophys. 54, 162-219 (2016).

18. A. V. Reyes et al., Nature 510, 525-528 (2014).

19. See the supplementary materials.

20. A. Schmittner et al., Paleoceanography 32, 512-530 (2017).
21. B. Corliss, X. Sun, C. Brown, W. Showers, Deep Sea Res. Part I Oceanogr. Res. Pap. 53, 740-746 (2006).

22. M. Eide, A. Olsen, U. S. Ninnemann, T. Johannessen, Global Biogeochem. Cycles 31, 515-534 (2017).

23. L. E. Lisiecki, M. E. Raymo, W. B. Curry, Nature 456, $85-88$ (2008).

24. L. G. Henry et al., Science 353, 470-474 (2016).

25. N. Bouttes, D. M. Roche, V. Mariotti, L. Bopp, Geosci. Model Dev. 8, 1563-1576 (2015)

26. J. F. McManus, R. Francois, J. M. Gherardi, L. D. Keigwin, S. Brown-Leger, Nature 428, 834-837 (2004).

27. R. Ferrari et al., Proc. Natl. Acad. Sci. U.S.A. 111, 8753-8758 (2014)

28. G. Vettoretti, W. R. Peltier, J. Clim. 31, 3423-3449 (2018)

29. B. Martrat et al., Science 317, 502-507 (2007).

30. C. R. W. Ellison, M. R. Chapman, I. R. Hall, Science 312 , 1929-1932 (2006)

31. J. A. L. Nicholl et al., Nat. Geosci. 5, 901-904 (2012).

32. R. G. Hatfield et al., Earth Planet. Sci. Lett. 454, 225-236 (2016).

33. M. E. Raymo et al., Paleoceanography 19, PA2008 (2004)

34. L. E. Lisiecki, M. E. Raymo, Paleoceanography 20, PA1003 (2005).

35. J. Laskar et al., Astron. Astrophys. 428, 261-285 (2004).

36. E. J. Colville et al., Science 333, 620-623 (2011).

37. L. E. Lisiecki, Clim. Past 6, 305-314 (2010).

38. C. Xuan, J. E. T. Channell, D. A. Hodell, Quat. Sci. Rev. 142 , 74-89 (2016)

\section{ACKNOWLEDGMENTS}

We thank the scientific party and crew of R/V JOIDES Resolution IODP Expedition 303, the curatorial staff at the IODP Bremen core repository for core sampling assistance, and D. Richmond for assistance with processing MIS 9e samples. Funding: This work was funded by grants from the Research Council of Norway (RCN) through the project THRESHOLDS (RCN grant 254964) and data generation at FARLAB (RCN grant 245907). Author contributions: U.S.N. and E.V.G. designed the project, and all coauthors helped conceptualize the study; E.V.G. processed the sediment samples and conducted the benthic and planktic foraminifera stable isotope analyses; N.I. conducted the IRD analyses; A.K., J.T., N.B., and

D.M.R. designed and performed the iLOVECLIM simulation; Y.R. performed the B/Ca analyses; and E.V.G. led the writing effort and coordinated input from all coauthors. Competing interests: None declared. Data and materials availability: The data are available in the supplementary materials.

\section{SUPPLEMENTARY MATERIALS}

science.sciencemag.org/content/367/6485/1485/suppl/DC1 Materials and Methods

Supplementary Text

Figs. S1 to S7

References (39-57)

Data S1

5 July 2019; accepted 11 February 2020

10.1126/science.aay6381 


\section{Science}

\section{Interglacial instability of North Atlantic Deep Water ventilation}

Eirik Vinje Galaasen, Ulysses S. Ninnemann, Augustin Kessler, Nil Irvali, Yair Rosenthal, Jerry Tjiputra, Nathaëlle Bouttes, Didier M. Roche, Helga (Kikki) F. Kleiven and David A. Hodell

Science 367 (6485), 1485-1489.

DOI: $10.1126 /$ science.aay6381

\section{Disrupting deep circulation}

Atlantic Meridional Overturning Circulation (AMOC) and the related process of North Atlantic Deep Water (NADW) have been thought to be stable during warm, interglacial periods. Galaasen et al. report that episodes of reduced NADW over the past 500,000 years actually have been relatively common and occasionally long-lasting features of interglacials and that they can occur independently of the catastrophic freshwater outburst floods normally thought to be their cause (see the Perspective by Stocker). This discovery implies that large NADW disruptions might be more likely than we have assumed in the warmer climate of the future.

Science, this issue p. 1485; see also p. 1425

ARTICLE TOOLS

\section{SUPPLEMENTARY} MATERIALS

RELATED

CONTENT

REFERENCES

PERMISSIONS http://science.sciencemag.org/content/367/6485/1485

http://science.sciencemag.org/content/suppl/2020/03/25/367.6485.1485.DC1

http://science.sciencemag.org/content/sci/367/6485/1425.full

This article cites 56 articles, 17 of which you can access for free http://science.sciencemag.org/content/367/6485/1485\#BIBL

http://www.sciencemag.org/help/reprints-and-permissions

Use of this article is subject to the Terms of Service

Science (print ISSN 0036-8075; online ISSN 1095-9203) is published by the American Association for the Advancement of Science, 1200 New York Avenue NW, Washington, DC 20005. The title Science is a registered trademark of AAAS.

Copyright @ 2020 The Authors, some rights reserved; exclusive licensee American Association for the Advancement of Science. No claim to original U.S. Government Works 